\title{
Asthma Among Staten Island Fresh Kills Landfill and Barge Workers Following the September 11 , 2001 World Trade Center Terrorist Attacks
}

\author{
James E. Cone, ${ }^{1 *}$ Sukhminder Osahan, ${ }^{1}$ Christine C. Ekenga, ${ }^{2}$ \\ Sara A. Miller-Archie, ' Steven D. Stellman, ${ }^{1,3}$ Monique Fairclough, ${ }^{1}$ \\ Stephen M. Friedman, ${ }^{1}$ and Mark R. Farfel ${ }^{1}$
}

\begin{abstract}
Background Although airborne respiratory irritants at the World Trade Center (WTC) site have been associated with asthma among WTC Ground Zero workers, little is known about asthma associated with work at the Staten Island landfill or barges.

Methods To evaluate the risk of asthma first diagnosed among Staten Island landfill and barge workers, we conducted a survey and multivariable logistic regression analysis regarding the association between Staten Island landfill and barge-related work exposures and the onset of post-9/11 asthma.

Results Asthma newly diagnosed between September 11, 2001 and December 31, 2004 was reported by 100/1,836 (5.4\%) enrollees. Jobs involving sifting, digging, welding, and steel cutting, enrollees with high landfill/barge exposure index scores or who were police and sanitation workers, and enrollees with probable posttraumatic stress disorder all had increased odds ratios for new-onset asthma.

Conclusions Post-9/11 asthma cumulative incidence among Staten Island landfill/barge workers was similar to that of other WTC disaster rescue and recovery workers. Am. J. Ind. Med. 59:795-804, 2016. (c) 2016 Wiley Periodicals, Inc.
\end{abstract}

KEY WORDS: occupational asthma; reactive airways dysfunction syndrome; World Trade Center

\section{INTRODUCTION}

Terrorist attacks in New York City (NYC) on September 11, 2001, destroyed the two World Trade Center (WTC) towers and numerous nearby buildings, with loss of several

${ }^{1}$ World Trade Center Health Registry, New York City Department of Health and Mental Hygiene, New York City, New York

${ }^{2}$ Division of Public Health Sciences, Washington University School of Medicine, St. Louis, Missouri

${ }^{3}$ Department of Epidemiology, Mailman School of Public Health, Columbia University, New York City, New York

${ }^{*}$ Correspondence to: Dr. James E. Cone, MD, MPH, Medical Director, World Trade Center Health Registry, 42-09 28th Street, 7th floor, Queens, NY 11101.

E-mail: jcone@health.nyc.gov

Accepted 14 June 2016

DOI 10.1002/ajim.22645. Published online in Wiley Online Library (wileyonlinelibrary.com). thousand lives and exposure of hundreds of thousands of workers, lower Manhattan residents, and others to trauma and hazardous materials with long-term physical and mental health effects [Galea et al., 2002; Prezant et al., 2002; Perlman et al., 2011; Luft et al., 2012; Brackbill et al., 2014].

Intense rescue efforts during the first few days after the attacks gave way to a 10-month clean-up operation and crime scene investigation. Between September 12, 2001 and July 31,2002 , nearly 2 million tons of debris at the WTC site (Ground Zero) were dismantled and transported by truck to lower Manhattan piers and then loaded onto barges for transfer to the Staten Island (SI) Fresh Kills Landfill (landfill) for processing as a part of the recovery efforts and criminal investigation [Mackinnon and Mundorff, 2007]. The crime scene investigation involved combining physical evidence with careful deductive and inductive reasoning by a multidisciplinary team to gain knowledge about the events 
surrounding the terrorist attack. The NYC Office of the Chief Medical Examiner (OCME) was responsible for sorting through an estimated 54,000 personal effects and over 20,000 human remains, resulting in the identification of $60 \%$ of the victims. [New York State Museum, 2004; WTC Operational Statistics, 2011; Goldenberg, 2015].

In addition to OCME employees, work at the landfill was largely performed by personnel of the NYC Police Department (NYPD), NYC Fire Department (FDNY), NYC Department of Sanitation (DSNY), the Federal Bureau of Investigation, construction workers, and volunteers affiliated with the American Red Cross, The Salvation Army, and other service organizations. An estimated 15,000 workers received training in the use of personal protective equipment in preparation for work at the landfill and on the barges [Phillips \& Jordan, Inc., 2004], but it is unknown how many of these trained workers actually worked on the landfill or barges.

Multiple health problems have been associated with exposure to the WTC disaster [Jordan et al., 2011; Perlman et al., 2011; Zeig-Owens et al., 2011; Li et al., 2012; Jordan et al., 2013; Solan et al., 2013]. Prior studies have described a high prevalence of respiratory symptoms of cough, wheezing and shortness of breath, and pulmonary conditions, including abnormal pulmonary function tests, and airway hyperreactivity. Diagnoses of reactive airways dysfunction syndrome (RADS) and asthma have been identified as major health outcomes from exposure to the WTC site [Prezant et al., 2002; Banauch et al., 2003; Wheeler et al., 2007; Brackbill et al., 2009; Aldrich et al., 2010; Weiden et al., 2010]. Both lifetime prevalence of asthma and 12-month asthma attack or episode rates were found to be elevated post-September 11, 2001 among WTC responders compared with the National Health Interview Survey population [Kim et al., 2012]. Asthma risk was highest among rescue and recovery workers who reported work on the WTC pile on September 11, 2001, and among those who worked the longest [Herbert et al., 2006; Farfel et al., 2008; Weakley et al., 2011; Lucchini et al., 2012]. However, respiratory health impacts of specific experiences of Staten Island Fresh Kills landfill and barge workers have not been well studied.

The goals of this study were to assess the potential association between work tasks, dust, and other respiratory irritant exposures and self-reported physician-diagnosed asthma among workers at the landfill and barges, and to assess cumulative incidence of new-onset asthma postSeptember 11, 2001.

\section{MATERIALS AND METHODS}

\section{Study Sample}

The WTC Health Registry (Registry) is a longitudinal cohort study of 71,431 unique individuals who were administered a baseline survey in 2003-2004 (Wave 1) [Perrin et al., 2007; Farfel et al., 2008; Brackbill et al., 2009]. The Registry includes rescue, recovery and cleanup workers, lower Manhattan area workers and passersby on September 11, 2001, lower Manhattan residents, school children, and school staff. Subsequently, two cohort-wide follow-up health surveys were conducted, in 2006-2007 (Wave 2) and 2011-2012 (Wave 3). The asthma data for this study were obtained from Waves 1 and 2 only.

The Registry includes rescue and recovery workers $(n=30,654)$, of whom 4,490 (14.6\%) reported work for at least one day at the landfill or barges. This included 460 FDNY and 1,108 NYPD workers. Approximately $21 \%$ $(n=940)$ of this Registry subgroup reported working exclusively at the landfill or barges.

\section{Data Collection}

The Registry's Wave 1 survey asked questions about exposure and physician diagnosis of asthma, and whether asthma was diagnosed before or after September 11, 2001. Wave 2 asked about asthma and RADS, year of diagnosis, and whether the diagnosis was pre- or post-September 11, 2001.

However, the Waves 1 and 2 survey questions regarding exposures experienced at the landfill and barges were relatively limited, compared with the details obtained regarding exposures at the WTC site. This led to a specialpurpose two-phase investigation: Phase I was a qualitative key informant interview study of landfill/barge workers; results have been published previously [Ekenga et al., 2011]. Findings from Phase I were used by the investigators to develop Phase II, an in-depth sub-group survey within the Registry cohort that was limited to the 4,490 rescue/recovery workers who said they worked at the landfill or barges on the Registry's Wave 1 survey. Excluded were those who were non-English speaking $(\mathrm{n}=36)$, and those who declined to be contacted for further studies $(n=300)$. The survey was distributed to the remaining 4,154 workers from June 2010 to November 2011.

\section{Study Population}

Enrollees who completed the landfill/barge survey, and confirmed that they worked at the landfill or barges, were included in this analysis if they also answered the Wave 2 survey. Of the 4,147 Registry enrollees eligible for this study, 2,287 participated in the landfill/barge worker survey (response rate $55 \%$ ) (Fig. 1). Of these 2,287 enrollees, 4 had a missing response for asthma, 266 enrollees indicated that they had never worked on SI or on the barges, and 9 had missing or discordant information for RADS and were not considered further. The subset of 172 enrollees with pre-September 11, 2001 asthma 


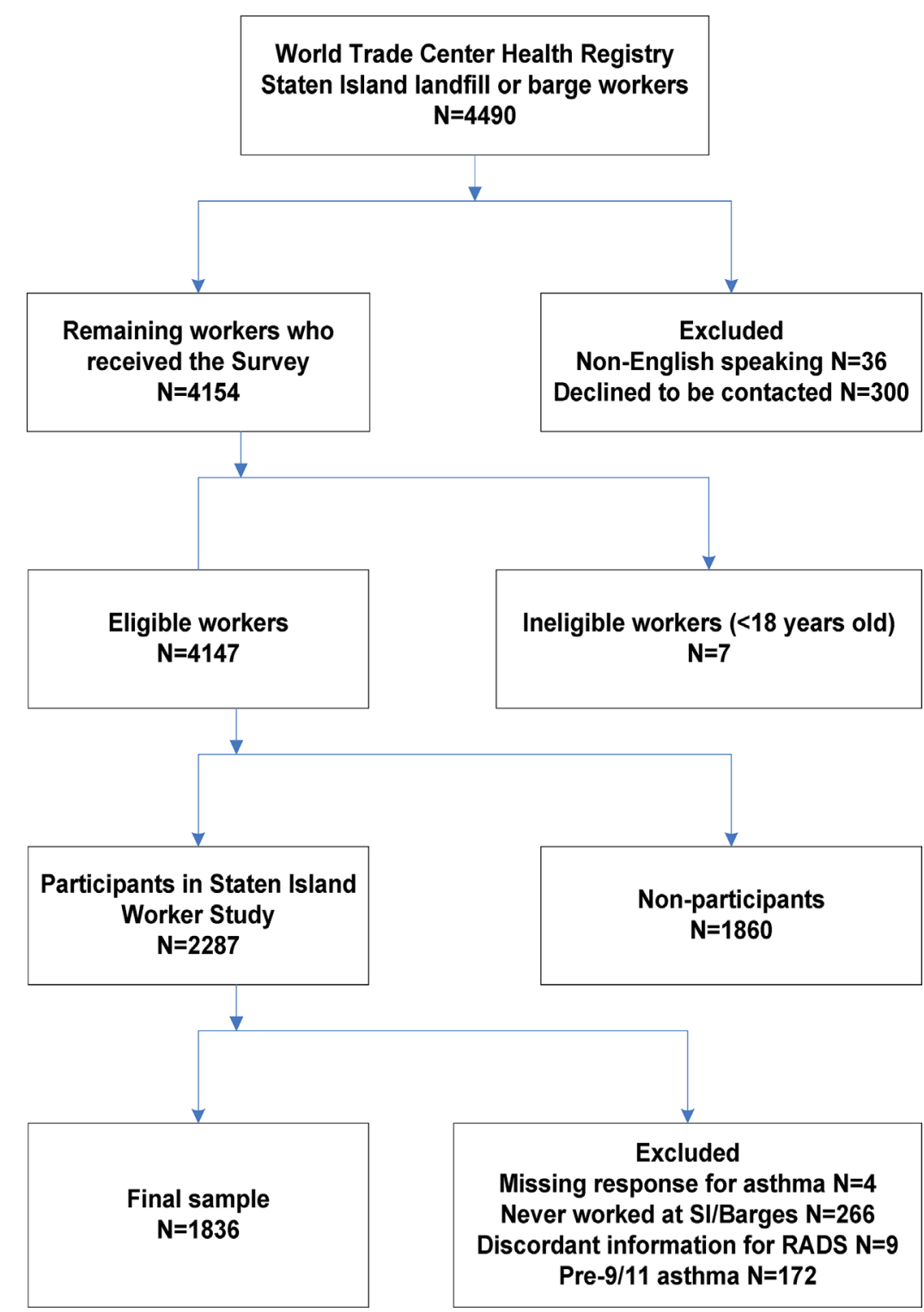

FIGURE 1. Flow chart of study population.

was also excluded. The final sample included 1,836 enrollees, with a total of 100 asthma cases diagnosed between September 11, 2001 and December 31, 2004. The cutoff date was based on the assumption that diagnoses of asthma during that period in persons with no previous asthma history were more likely to be associated with September 11, 2001 exposures, and is supported by the decline of the annualized incidence rate for asthma in the Registry population by the end of 2004 [Brackbill et al., 2009].

\section{Study Variables}

Demographic information, exposures, and health outcomes, including self-reported physician diagnosis of asthma, were obtained from the Wave 1 survey. Subsequent health outcomes were obtained from the Wave 2 survey, including self-reported physician-diagnosed asthma and RADS, and year of diagnosis. RADS cases were included in light of the reported exposures to respiratory irritants [Brooks et al., 1985]. Cases of selfreported physician diagnosis of post-September 11, 2001 asthma or RADS (hereafter called simply "asthma") were included in this analysis if they reported a physician diagnosis of post-September 11, 2001 asthma on Wave 1, or if on Wave 2 they reported a physician diagnosis of asthma or RADS occurring in 2001 (post-September 11, 2001, 2002, 2003, or 2004). The reported asthma diagnosis dates were restricted to the interval between the terrorist attacks and December 31, 2004. 


\section{SI Exposure Scale and Other Work-Related Variables}

We used three distinct, complementary methods to assess exposure, based on data from the landfill/barge-specific survey: (i) a work exposure index based on seven self-reported specific types of exposure and protective factors including use of shower facilities, and frequency of wearing a Tyvek suit, Nomex suit, or other disposable protective suit; (ii) exposure assessment by a panel of experts using a modified Delphi process, to be described below, based on 17 specific job titles/ tasks; and (iii) the identity of the enrollee's employer. We also evaluated the potential contribution of dust cloud exposure, defined as a positive response to the Wave 1 question: "On September 11th, were you outdoors within a dust or debris cloud resulting from the collapse of the World Trade Center towers?" This applies to those who were in lower Manhattan on the morning of September 11, 2001.

Disaster-related exposures specific to the landfill/barge workers were obtained from the landfill/barge-specific survey, including tasks performed, experience with prior disasters, training, location and dates of work, encountering human remains, exposure to dust, fumes or odors, and wearing of protective equipment.

\section{Method 1}

Using information obtained in the Phase I qualitative study of landfill/barge workers [Ekenga et al., 2011], we constructed a landfill/barge worker exposure scale using participant responses to seven questions: (i) "How often did you breathe in dust from the debris piles, construction activities, sorting activities, or unpaved roads"; (ii) "How often did you see dust in the air at your worksite"; (iii) "How often was visibility impaired at your worksite"; (iv) "How often did you breathe in diesel or gasoline fumes at your worksite"; (v) "How often did you breathe in garbage odors"; (vi) "How often did you wear a Tyvek suit, Nomex suit, or any other disposable protective suit"; and (vii) "How often did you use the shower facilities at Fresh Kills Landfill?" The possible answers included: "Every day," (scored as 4), "Almost every day," (3) "Some days," (2) "Almost never," (1) and "Never" (0). Questions (vi) and (vii) were scored in the opposite manner to reflect their potential protective effect with "Never" scored as 4 and "Every day" scored as 0 . Due to the relatively small number of responses to the respiratory protection questions, respiratory protection use was not included in this scale. The exposure scale ranged from 0 to 28 , with high exposure classified as a score of $\geq 15$. This scale was found to have good reliability (Cronbach's $\alpha=0.84$ ).

\section{Method 2}

A modified Delphi process [Dalkey and Helmer, 1963; Levy et al., 2004; Hsu and Sandford, 2007] was designed to better categorize the 17 landfill/barge-specific job titles and tasks identified in the Phase I qualitative study by their level of airborne irritant exposure [Ekenga et al., 2011]. (Please see Supplementary Appendix for a description of the Delphi method.) The Delphi process was conducted via e-mail. The authors nominated candidate experts based on their experience and knowledge of the post-September 11, 2001 SI landfill/barge processes. Six nominees were sent invitations to participate. Each of the three experts who agreed to participate was provided with detailed instructions and a listing of job tasks used in the follow-up landfill/barge worker survey, and offered additional information about job tasks, including the available 2001-2002 Occupational Safety and Health Administration air sampling data for the SI site obtained for limited time periods and a relatively small number of specific tasks. The results of the first round were provided to each participant during Round 2. Following Round 2, job tasks were categorized into four hierarchical levels of exposure (Table II), with those who reported working in any job task categorized in the highest level assigned to that level, and those who had not worked in any of the highest level job tasks, but who had worked in any of the second highest level tasks, assigned to that level, and so on until all were assigned an exposure level based on job task.

\section{Method 3}

The enrollee's employer as of September 11, 2001, obtained from the Wave 1 survey, was used to categorize workers as FDNY, NYPD, DSNY, and all other employers.

We examined reported acute injury [Brackbill et al., 2014] and PTSD [Brackbill et al., 2009] because each of these has been associated with increased risk of postSeptember 11, 2001 asthma in prior studies.

Injuries sustained on September 11, 2001 were reported at Wave 1 and classified by type as: cut, abrasion, or puncture wound; sprain or strain; burn; broken bone (fracture) or dislocation; and "concussion/head injury/knocked out by being hit on the head." These injuries have been found to be associated in the Registry cohort with later occurrence of chronic disease including cardiovascular diseases, asthma, and other respiratory conditions [Brackbill et al., 2014].

Enrollees completed the PTSD Checklist-Specific Version (PCL). The PCL is a 17-item self-reported symptom scale derived from the Diagnostic and Statistical Manual of Mental Disorders, Fourth Edition (DSM-IV) diagnostic criteria in three symptom clusters: intrusive and reexperiencing, numbing and avoidance, and hyperarousal. Each item is scored from 1 (not at all) to 5 (extremely). We summed responses to the 17 items and defined probable PTSD as meeting a Wave 1 PCL criteria of 44 or more and the presence of at least one re-experiencing symptom (DSM-IV criterion B), three avoidance or numbing symptoms (DSM-IV criterion C), and two hyperarousal 
symptoms (DSM-IV criterion D). We used the dual criteria to obtain a more conservative estimate of probable PTSD than by PCL score alone [DiGrande et al., 2008].

\section{Data Analysis}

SAS version 9.2 was used for all analyses. A two-sided $P$-value of $P<0.05$ was considered significant for hypothesis tests.

We calculated the cumulative incidence of new-onset asthma diagnosed sometime between September 12, 2001 and December 31, 2004, among the landfill and barge workers.

Bivariate analysis was used to evaluate frequencies of asthma by demographic variables, smoking status, and $9 / 11$ exposures. The $\chi^{2}$ test was used to assess potential bivariate associations. A multivariable logistic regression model was used to estimate adjusted odds ratios (aOR) and 95\% confidence intervals (CI) for asthma. Covariates were selected a priori based on (i) previous research in both 9/11-exposed and other populations; and (ii) biological plausibility. Demographic characteristics included in the logistic regression model were age, gender, race/ethnicity, marital status, and level of education. In addition, the multivariable model included smoking, occupation, work exposure index score, dust cloud exposure, work start date, having also worked at Ground Zero, being injured on 9/11, and probable PTSD. The sample size for three of the four Delphi method-based exposure categories was too small to allow for computation of adjusted odds ratios, so only unadjusted odds ratios were calculated for this analysis.

This study was approved by the Institutional Review Boards (IRBs) for the NYC Department of Health and Mental Hygiene (DOHMH) and the United States Centers for Disease Control and Prevention. Oral informed consent was obtained from participants prior to enrollment.

\section{RESULTS}

\section{Selection}

The study enrollees (Table I) were mostly male, between ages 18 and 44, with at least some college education, and were married. Almost half reported a history of smoking. Nearly $84 \%$ reported high levels of SI-specific work exposures, and $75 \%$ also worked at the WTC site in lower Manhattan. Members of the NYPD comprised 30\% of the study population, followed by DSNY workers (18\%), FDNY workers (12\%), and the remaining $40 \%$ working for other employers or volunteer service agencies. At Wave 1,8\% had probable PTSD based on their PCL score.

While educational attainment of the 2,287 landfill/barge survey participants was not significantly different from that of the 1,860 non-participants, participants were more likely to be older, white, male, married, and were less likely to have probable PTSD at Wave 1. Study participants were also significantly less likely to have worked at Ground Zero (data not shown).

\section{Post-September 11, 2001 Asthma Incidence (2001-2004)}

The cumulative incidence of reported physiciandiagnosed asthma/RADS among landfill and barge workers September 11, 2001 through December 31, 2004 was 5.4\% (95\% CI $4.5-6.6 \%)$.

The proportions of newly diagnosed post-September 11, 2001 asthma cases were highest among females, those aged 18-44, Hispanic/Latino and multi/other racial workers, those with a high school degree or less, former smokers, and never married, although only the contrast between never married and the combination of married and/or widowed was statistically significant.

The results in Table I include adjusted odds ratios for all variables included in the model, with observed significant associations between asthma and female gender (aOR 2.1, 95\% CI 1.1-3.8), education less than college (aOR 1.6, 95\% CI 1.0-2.5) and reporting symptoms consistent with probable PTSD at Wave 1 (aOR 2.5, 95\% CI 1.4-4.5).

Factors not significantly associated in multivariable analyses with asthma diagnosis between 2001 and 2004 included age, race/ethnicity, smoking status at Wave 1, reported injuries on September 11, 2001, work start period, and whether individuals had also worked at Ground Zero.

\section{Exposure Reconstruction}

An elevated work exposure index score (Table I) was associated with increased odds of asthma (aOR 2.5, 95\% CI 1.0-6.1). Multivariable analysis also showed significant associations between asthma and work for the NYPD (aOR 2.0, 95\% CI 1.2-3.5), but not for work for FDNY, or DSNY, compared with other employers.

Dust cloud exposure (reported at Wave 1) was associated with a $60 \%$ increased odds of asthma, although this was not statistically significant (aOR 1.6, 95\% CI 1.0-2.5).

The frequency of post-9/11 asthma within each of the four job task groups identified using the Delphi process is shown in Table II. Activities assigned to the highest exposure category involved sifting by hand, digging or earth moving, sanitation work (loading/dumping), welding, and steel cutting (Group 4). A total of 1,114 workers reported working on one or more of these tasks on SI. Of these workers, 80 reported a diagnosis of new-onset asthma between 2001 and 2004. Significantly increased odds of asthma was associated with reporting of any tasks included in the group (Group 4) of highest exposure 
TABLE I. Reported Frequency and Adjusted Odds Ratios for Post-September 11, 2001 Asthma Among SI Landfill/Barge Workers (N = 1836)

\begin{tabular}{|c|c|c|c|}
\hline Characteristic & Total N (\%) & Asthma cases N (\%) & $\operatorname{AOR}(95 \% \mathrm{CI})^{\mathrm{a}}$ \\
\hline Total & $1,836(100.0)$ & $100(5.4)$ & \\
\hline \multicolumn{4}{|l|}{ Demographics } \\
\hline \multicolumn{4}{|l|}{ Gender } \\
\hline Male & $1,589(86.5)$ & $81(5.1)$ & $1.0(\mathrm{ref})$ \\
\hline Female & $247(13.5)$ & $19(7.7)$ & $2.1(1.1-3.8)$ \\
\hline \multicolumn{4}{|l|}{ Age on 9/11 (yrs) } \\
\hline $18-44$ & $1,092(59.5)$ & $64(5.9)$ & $0.8(0.5-1.3)$ \\
\hline $45+$ & $744(40.5)$ & $36(4.8)$ & $1.0(\mathrm{ref})$ \\
\hline \multicolumn{4}{|l|}{ Race/ethnicity } \\
\hline Hispanic/Latino or multiracial & 209 (11.4) & $16(7.7)$ & $1.3(0.7-2.3)$ \\
\hline White, Black, or Asian & $1,627(88.6)$ & $84(5.2)$ & $1.0(\mathrm{ref})$ \\
\hline \multicolumn{4}{|l|}{ Marital status } \\
\hline Married or living with partner & $1,467(80.0)$ & $74(5.0)$ & 1.0 (ref) \\
\hline Widowed, divorced, or separated & $189(10.3)$ & $10(5.3)$ & $0.9(0.5-1.9)$ \\
\hline Never married & $177(9.7)$ & $16(9.0)$ & $1.6(0.9-2.9)$ \\
\hline \multicolumn{4}{|l|}{ Education } \\
\hline High school or less & $597(32.6)$ & $38(6.4)$ & $1.6(1.0-2.5)$ \\
\hline Some college or more & $1,232(67.4)$ & $62(5.0)$ & $1.0(\mathrm{ref})$ \\
\hline \multicolumn{4}{|l|}{ Smoking status } \\
\hline Never & $996(54.4)$ & $49(4.9)$ & 1.0 (ref) \\
\hline Former & $538(29.4)$ & $35(6.5)$ & $1.5(0.9-2.4)$ \\
\hline Current & $297(16.2)$ & $16(5.4)$ & $1.1(0.6-1.9)$ \\
\hline \multicolumn{4}{|l|}{ 9/11 Exposures } \\
\hline \multicolumn{4}{|l|}{ Occupation } \\
\hline NYPD & $553(30.1)$ & $44(8.0)$ & $2.0(1.2-3.5)$ \\
\hline FDNY & $214(11.7)$ & $14(6.5)$ & $1.8(0.8-3.9)$ \\
\hline DSNY & $331(18.0)$ & $13(3.9)$ & $0.8(0.4-1.8)$ \\
\hline Other & $738(40.2)$ & $29(3.9)$ & $1.0(\mathrm{ref})$ \\
\hline \multicolumn{4}{|l|}{ Work exposure index score } \\
\hline $0-14$ (low) & $293(16.1)$ & $6(2.0)$ & $1.0(\mathrm{ref})$ \\
\hline 15-28 (high) & $1,522(83.9)$ & $94(6.2)$ & $2.5(1.0-6.1)$ \\
\hline \multicolumn{4}{|l|}{ Dust cloud exposure } \\
\hline Yes & $695(38.0)$ & $55(7.9)$ & $1.6(1.0-2.5)$ \\
\hline No & $1,136(62.0)$ & $45(4.0)$ & 1.0 (ref) \\
\hline \multicolumn{4}{|l|}{ Work start period } \\
\hline First (September 12-30, 2001) & $1,022(56.4)$ & $60(5.9)$ & $1.0(0.6-1.6)$ \\
\hline $\begin{array}{l}\text { Second (0ctober } 1 \text {-December } 31,2001 \text { ) or } \\
\text { third (January } 1 \text {-June } 30,2002)\end{array}$ & $789(43.6)$ & $39(4.9)$ & 1.0 (ref) \\
\hline \multicolumn{4}{|l|}{ Sites worked } \\
\hline SI barges/landfill and WTC site & $1,383(75.3)$ & $84(6.1)$ & $1.0(0.5-1.9)$ \\
\hline SI barges/landfill only & $453(24.7)$ & $16(3.5)$ & 1.0 (ref) \\
\hline \multicolumn{4}{|l|}{ Injured on 9/11 } \\
\hline Yes & $293(16)$ & $24(8.2)$ & $1.2(0.7-2.0)$ \\
\hline No & $1,543(84)$ & $76(4.9)$ & 1.0 (ref) \\
\hline \multicolumn{4}{|l|}{ Posttraumatic stress disorder ${ }^{b}$} \\
\hline Yes & $142(7.9)$ & $19(13.4)$ & $2.5(1.4-4.5)$ \\
\hline No & $1,664(92.1)$ & $80(4.8)$ & 1.0 (ref) \\
\hline
\end{tabular}

NYPD, New York City Police Department; FDNY, Fire Department of New York City; DSNY, New York City Department of Sanitation.

${ }^{a}$ Adjusted odds ratio and $95 \%$ confidence interval. Model adjusted for all variables in the table. Statistically significant AORs are in bold.

${ }^{\mathrm{b}}$ PTSD Checklist cut-off $=44$ plus meeting DSM-IV criteria. 
TABLE II. Reported Frequency and Unadjusted Odds Ratios for PostSeptember 11, 2001 Asthma Among SI Landfill/Barge Workers by Job Task $(\mathrm{N}=1836)$

\begin{tabular}{|c|c|c|c|}
\hline Work activities group & $\begin{array}{l}\text { Total } \\
\text { (N) }\end{array}$ & $\begin{array}{c}\text { Asthma cases } \\
\text { N (\%) }\end{array}$ & $\mathrm{OR}(95 \% \mathrm{CI})^{\mathrm{a}}$ \\
\hline Total & 1,836 & $100(5.4)$ & \\
\hline \multicolumn{4}{|l|}{ Group1 } \\
\hline \multicolumn{4}{|l|}{$\begin{array}{l}\text { Barge supervision or } \\
\text { management }\end{array}$} \\
\hline \multicolumn{4}{|l|}{$\begin{array}{l}\text { Food service or support } \\
\text { activities }\end{array}$} \\
\hline \multicolumn{4}{|l|}{ Security } \\
\hline Tugboat work & 344 & $10(2.9)$ & 1.0 (ref) \\
\hline \multicolumn{4}{|l|}{ Group 2} \\
\hline \multicolumn{4}{|l|}{ Barge work } \\
\hline \multicolumn{4}{|l|}{$\begin{array}{l}\text { Equipment maintenance or } \\
\text { cleaning }\end{array}$} \\
\hline \multicolumn{4}{|l|}{ Truck driving } \\
\hline \multicolumn{4}{|l|}{$\begin{array}{l}\text { Vehicle maintenance or } \\
\text { cleaning }\end{array}$} \\
\hline $\begin{array}{l}\text { Barge maintenance or } \\
\text { cleaning }\end{array}$ & 109 & $2(1.8)$ & $0.6(0.1-2.9)$ \\
\hline \multicolumn{4}{|l|}{ Group 3} \\
\hline \multicolumn{4}{|l|}{ Crime scene investigation } \\
\hline \multicolumn{4}{|l|}{ Gas powered tool operation } \\
\hline \multicolumn{4}{|l|}{ Heavy equipment operation } \\
\hline $\begin{array}{l}\text { Landfill supervision or } \\
\text { management }\end{array}$ & 224 & $8(3.6)$ & $1.2(0.5-3.2)$ \\
\hline \multicolumn{4}{|l|}{ Group 4} \\
\hline \multicolumn{4}{|l|}{ Digging or earth moving } \\
\hline \multicolumn{4}{|l|}{$\begin{array}{l}\text { Sanitation work (loading or } \\
\text { dumping) }\end{array}$} \\
\hline \multicolumn{4}{|l|}{$\begin{array}{l}\text { Sifting by hand, conveyor } \\
\text { belt, or rake }\end{array}$} \\
\hline $\begin{array}{l}\text { Welding, steel cutting, or } \\
\text { torch operation }\end{array}$ & 1,114 & $80(7.2)$ & $2.6(1.3-5.0)$ \\
\hline
\end{tabular}

Cochran-Armitage Trend Test is significant at $P<0.01$.

${ }^{a}$ Unadjusted odds ratio and $95 \%$ confidence interval. Statistically significant ORs are in bold.

activities (Unadjusted OR 2.6, 95\% CI 1.3-5.0) compared with those who reported working only on the lowest exposure task group (Group 1). A test for trend was also statistically significant (Cochran-Armitage Trend Test: $P<0.01$ ).

The number of responses to the respiratory protection questions were not sufficient for meaningful statistical analyses.

\section{DISCUSSION}

Increased work-related exposure to respiratory irritants on the landfill/barges during the cleanup following the WTC disaster was associated with new-onset asthma. Our results extend the previous findings of increased asthma among September 11, 2001-exposed rescue and recovery workers by examining the asthma-workplace exposure relationship among the subgroup of recovery workers deployed at the landfill and barges. A previous study of rescue/recovery workers enrolled in the Registry found that those who worked on the pile on September 11th and those who worked more than 90 days had twice the odds of incident asthma (aOR 2.2 95\% CI 1.9-2.6 and aOR 1.9 95\% CI 1.6-2.1, respectively) [Brackbill et al., 2009].

The cumulative incidence of asthma and RADS reported in landfill/barge workers between September 11, 2001 and December 31, 2004 was $5.4 \%$. This was very similar to the cumulative incidence of asthma and RADS among all Registry rescue and recovery workers over the same time period, 5.6\% [Brackbill et al., 2009]. Other WTC-exposed responder populations have reported increased rates of asthma as well as active disease in their cohorts [Prezant, 2008; Webber et al., 2011; Kim et al., 2012].

Exposure at the SI landfill/barges was different from exposure at Ground Zero in several key respects: exposure at Ground Zero was likely greatest on the morning of September 11, 2001, with consistently elevated relative risk estimates for those who started work then. Exposure at the landfill/barges started on September 12, 2001. The presence of potential respiratory irritants at the landfill prior to Delphi technique: Making sense of consensus suggests that there may have been possible respiratory health effects of the landfill itself combined with WTC-specific exposures.

No objective measures exist that can assess the levels and frequency of respiratory irritant exposure experienced by workers on the SI landfill and barges, which required us to construct multiple alternate methods to estimate this exposure. We found that the three measures of work exposure used in this study all arrived at similar conclusions, namely that workers who experienced the highest levels of respiratory irritant exposure had the highest odds of developing asthma. For example, the greater specificity of job tasks obtained in the landfill/barge worker survey enabled grouping of those tasks with highest potential risk (sifting by hand, digging, welding, and steel cutting), and there was a significant increasing trend in asthma with increasing level of exposure measured by the Delphi method.

Exposure to the landfill itself, even prior to the events of September 11, 2001, was of concern. The 2,200 acre SI site had served as the principal garbage disposal site for NYC between 1947 and March, 2001. Background exposures specific to the Fresh Kills landfill and barges thus included bacteria, dusts, metals, and other hazardous materials. Prior to September 11, 2001, Gelberg found a higher prevalence of work-related dermatological, neurological, hearing, and respiratory symptoms among DSNY landfill workers than in a comparable group of workers not 
exposed to the Fresh Kills landfill [Gelberg, 1997]. Data on asthma in this population prior to September 11, 2001 were not systematically collected and thus were not included in this publication.

A prior Registry study [Antao et al., 2011] found that those who used respirators were less likely to report adverse respiratory outcomes compared to those who reported no/lower levels of respiratory protection. However, a major limitation of the current study is that relatively few workers responded to the landfill/barge worker survey questions regarding the use of respiratory protection. Mask/respirator use was discussed as part of the prior qualitative study [Ekenga et al., 2011], where participants reported that enforcement of mask and respirator use varied, and some workers never received respiratory protection. Problems using respiratory protection were noted particularly among participants reporting that their jobs required frequent radio communications.

Another limitation of this study is that the asthma observed among the $75 \%$ of workers who were at both Ground Zero and the SI landfill and barge sites could have been a result of their combined exposures to WTC-related dust or other respiratory irritants at both locations, rather than specifically related to their work on the landfill/barges.

Another important limitation of this study is its reliance on self-reported physician diagnosis of asthma. However, a recent study of FDNY members found that self-reported asthma had high sensitivity (68.7\%) and overall agreement (91.9\%) with diagnoses recorded on medical records [Weakley et al., 2013]. Other Registry self-reported medical conditions have also been validated, including self-reported cancer diagnoses among Registry enrollees that found high sensitivity (83.9\%) and specificity $(98.5 \%)$ after comparing survey data to state cancer registries and medical records [Li et al., 2016].

We were also unable to determine the relative accuracy of reported diagnoses of asthma compared with that of reported diagnoses of RADS. For example, 11 enrollees reported that they were diagnosed with asthma on the Wave 1 survey, but reported that they were diagnosed with RADS on the Wave 2 survey. It is controversial whether repeated low-level exposure to irritant substances such as occurred, for example, at the landfill/barges, can lead to RADS [Tarlo 2000; Youakim, 2001].

Over 9 years elapsed between September 11, 2001 and the landfill/barge survey, which may have resulted in recall bias, resulting in possible overestimation of the true prevalence of asthma. The relatively moderate response rate for the landfill/barge worker survey may have resulted in response bias, which may also have resulted in overestimation of the true risk [Murphy et al., 2005] although attrition from the WTC Health Registry follow-up studies does not appear to lead to serious bias in associations between September 11, 2001 disaster exposures and key health outcomes [Yu et al., 2015].
In addition, measures of association can only be compared between those who experienced higher versus lower levels of landfill/barge-related exposure, as we did not have a comparable external comparison group of workers who did not experience any 9/11-related exposures.

Additional limitations include the relatively small sample sizes for some analyses and the resulting reduced power.

\section{CONCLUSIONS}

The cumulative incidence of post-9/11 asthma was similar among SI landfill/barge workers to that of the rescue and recovery workers on the WTC site. Future disaster cleanup and crime scene operations need to consider additional interventions to reduce the risk of asthma and other adverse health outcomes among workers. Research is needed on the feasibility of engineering controls such as physical isolation of dust-producing processes with enclosures, enhanced dust suppression techniques, and improved personal respiratory protective equipment to address the problems faced with workers who need to communicate while adequately protected. Screening for asthma and ensuring adequate access to high quality treatment are essential for affected workers following disasters involving exposure to respiratory irritants. The observed comorbidity of asthma with PTSD increases the challenge of providing affected workers with appropriate treatment for both conditions.

\section{AUTHORS' CONTRIBUTIONS}

The authors declare that all participated as follows:

- Substantial contributions to the conception or design of the work; or the acquisition, analysis, or interpretation of data for the work; and

- Drafting the work or revising it critically for important intellectual content; and

- Final approval of the version to be published; and

- Agreement to be accountable for all aspects of the work in ensuring that questions related to the accuracy or integrity of any part of the work are appropriately investigated and resolved.

\section{ACKNOWLEDGMENTS}

We would like to thank Robert Brackbill, $\mathrm{PhD}$, Charon Gwynn, PhD, Sharon Perlman, MPH, Carolyn Greene, MD, James L. Hadler, MD, MPH, Carey Maslow, PhD, Alexander Davidson, MPH, and Margaret Millstone, from the NYC Department of Health and Mental Hygiene, for their thoughtful comments, guidance, and support on this 
manuscript. Thanks also to Chris D'Andrea, MPH, Michael McCann, $\mathrm{PhD}$, and Lorna Thorpe, $\mathrm{PhD}$ for their assistance with categorizing landfill and barge job tasks.

\section{FUNDING}

This work was supported by National Institute for Occupational Safety and Health (NIOSH) of the Centers for Disease Control and Prevention (CDC). Cooperative Agreement Number: 5U50/OH009739; Agency for Toxic Substances and Disease Registry (ATSDR), CDC. Cooperative Agreement Number: U50/ATU272750, which included support from the National Center for Environmental Health, CDC. In addition, funding was received from the New York City Department of Health and Mental Hygiene (NYC DOHMH).

\section{ETHICS APPROVAL AND INFORMED CONSENT}

Oral informed consent was obtained from participants prior to enrollment.

\section{DISCLOSURE (AUTHORS)}

The authors report no conflicts of interest.

\section{DISCLOSURE BY AJIM EDITOR OF RECORD}

Paul Landsbergis declares that he has no competing or conflicts of interest in the review and publication decision regarding this article.

\section{DISCLAIMER}

The contents of this report are solely the responsibility of the authors and do not necessarily represent the official views of NIOSH-CDC.

\section{REFERENCES}

Aldrich TK, Gustave J, Hall CB, Cohen HW, Webber MP, Zeig-Owens R, Cosenza K, Christodoulou V, Glass L, Al-Othman F, et al. 2010. Lung function in rescueworkers at the World Trade Center after 7 years. N Engl J Med 362(14):1263-1272.

Antao V, Pallos L, Shim Y, Sapp JH, Brackbill RM, Cone JE, Stellman SD, Farfel MR. 2011. Respiratory protective equipment, mask use and respiratory outcomes among WTC rescue and recovery workers. Am J Industrial Med 54:897-905.

Banauch G, Alleyne D, Sanchez R, Olender K, Cohen HW, Weiden M, Kelly KJ, Prezant DJ. 2003. Persistent hyperreactivity and reactive airway dysfunction in firefighters at the World Trade Center. Am J Respir Crit Care Med 168:54-62.

Brackbill RM, Hadler JL, DiGrande L, Ekenga CC, Farfel MR, Friedman S, Perlman SE, Stellman SD, Walker DJ, Wu D, et al. 2009. Asthma and posttraumatic stress symptoms 5 to 6 years following exposure to the World Trade Center terrorist attack. JAMA 302:502-516.

Brackbill RM, Cone J, Farfel MR, Stellman SD. 2014. Chronic physical health consequences of being injured during the terrorist attacks on World Trade Center on September 11, 2001. Am J Epidemiology 179:1076-1085.

Brooks SM, Weiss MA, Bernstein IL. 1985. Reactive airways dysfunction syndrome (RADS) — Persistent asthma syndrome after high level irritant exposures. Chest 88:376-384.

Dalkey NC, Helmer O. 1963. An experimental application of the Delphi method to the use of experts. Manage Sci 9:458-467.

DiGrande L, Perrin M, Thorpe L, Thalji L, Murphy J, Wu D, Farfel M, Brackbill RM. 2008. Posttraumatic stress symptoms (PTSD) and risk factors among lower Manhattan residents 2-3 years after the September 11, 1001 terrorist attacks. J Traumatic Stress 21:264-273.

Ekenga CC, Scheu KE, Cone JE, Stellman SD, Farfel MR. 2011. September 11, 2001 -Related experiences and tasks of landfill and barge workers: Qualitative analysis from the WTC health registry. BMC Public Health 11:321.

Farfel M, DiGrande L, Brackbill R, Prann A, Cone J, Friedman S, Walker DJ, Pezeshki G, Thomas P, Galea S, et al. 2008. An overview of September 11, 2001 experiences and respiratory and mental health conditions among World Trade Center health registry enrollees. J Urban Health 85:880-909.

Galea S, Ahern J, Resnick H, Kilpatrick D, Bucuvalas M, Gold J, Vlahov D. 2002. Psychosocial sequelae of the September 11th terrorist attacks in New York City. New Engl J Med 346:982-987.

Gelberg KH. 1997. Health study of New York City Department of Sanitation landfill employees. J Occup Environ Med 39:1103-1110.

Goldenberg G. 2015. Speaking for the dead, caring for the living. NYU Physician Winter 19-21.

Herbert R, Moline J, Skloot G, Metzger K, Baron S, Luft B, Markowitz S, Udasin I, Harrison D, Stein D, et al. 2006. The World Trade Center disaster and the health of workers: Five-year assessment of a unique medical screening program. Environ Health Perspect 114:1853-1858.

Hsu C, Sandford B. 2007. The Delphi technique: Making sense of consensus. Practical assessment. Res Eval 12:1-10.

Jordan HT, Brackbill RM, Cone JE, Debchoudhury I, Farfel MR, Greene CM, Hadler JL, Kennedy J, Li J, Liff J, et al. 2011. Mortality among survivors of the Sept 11, 2001, World Trade Center disaster: Results from the WTC health registry cohort. Lancet 378:879-887.

Jordan H, Stellman S, Morabia A, Miller-Archie SA, Alper H, Laskaris Z, Brackbill RM, Cone JE. 2013. Cardiovascular disease hospitalizations in relation to exposure to the September 11, 2001 World Trade Center disaster and posttraumatic stress disorder. J Am Heart Assoc 2: e000431.

Kim H, Herbert R, Landrigan P, Markowitz SB, Moline JM, Savitz DA, Todd AC, Udasin IG, Wisnivesky J, et al. 2012. Increased rates of asthma among WTC disaster responders. Am J Industrial Med 55:44-53.

Levy DT, Mumford EA, Cummings KM, Gilpin EA, Giovino G, Hyland A, Sweanor D, Warner KE. 2004. The relative risks of a lownitrosamine smokeless tobacco product compared with smoking cigarettes: Estimates of a panel of experts. Cancer Epidemiol Biomarkers Prev 13:2035-2042. 
Li J, Cone JE, Kahn AR, Brackbill RM, Farfel MR, Greene CM, Hadler JL, Stayner LT, Stellman SD. 2012. Association between World Trade Center exposure and excess cancer risk. JAMA 308:2479-2488.

Li J, Cone JE, Alt AK, Wu DR, Liff JM, Farfel MR, Stellman SD. 2016. Performance of self-reporting to establish cancer diagnoses in disaster responders and survivors, World Trade Center health registry, New York, 2001-2007. Public Health Rep 131:420-429.

Lucchini RG, Crane MA, Crowley L, Globina Y, Milek DJ, Boffetta P, Landrigan PJ. 2012. The World Trade Center health surveillance program: Results of the first 10 years and implications for prevention. G Ital Med Lav Ergon 34(3 Suppl):529-533.

Luft BJ, Schechter C, Kotof R, Brihier J, Reissman D, Guerrera K Udasin I, Moline J, Harrison D, Friedman-Jimenez G, et al. 2012 Exposure, probable PTSD and lower respiratory illness among World Trade Center rescue, recovery and clean-up workers. Psychological Med 42:1069-1079.

Mackinnon G, Mundorff A. 2007. The World Trade Center-September 11, 2001. In: Thompson T, Black S, editors. Forensic human identification: An introduction. Boca Raton: CRC Press, Taylor and Francis Group. pp. 485-499.

Murphy J, Brackbill R, Sapp JH II, Thalji L, Pulliam P. 2005. An analysis of nonresponse bias in the World Trade Center health registry. Proceedings of the American Statistical Association, Section on Survey Research Methods 2005 3422-3426.

New York State Museum. Recovery: The World Trade Center Recovery Operation at Fresh Kills. http://www.nysm.nysed.gov/ exhibits/traveling/recovery/documents/RecBro.pdf Accessed 1/26/ 2015 .

Perlman SE, Friedman S, Galea S, Nair HP, Eros-Sarnyai M, Stellman SD, Hon J, Greene CM. 2011. Short-term and medium-term health effects of September 11. Lancet 378:925-934.

Perrin M, DiGrande L, Wheeler K, Thorpe L, Farfel M, Brackbill R. 2007. Differences in PTSD prevalence and associated risk factors among World Trade Center disaster rescue and recovery workers. Am J Psychiat 164:1385-1394.

Phillips \& Jordan, Inc. 2004. Anatomy: World Trade Center/Staten Island Landfill recovery operation. http://911depository.info/PDFs/ Other\%20Reports/ Accessed 2/12/2015.

Prezant D, Weiden M, Banauch GI, McGuinness G, Rom WN, Aldrich TK, Kelly JK. 2002. Cough and bronchial responsiveness in firefighters at the World Trade Center site. New Engl J Med 347:806-815.

Prezant DJ. 2008. WTC cough syndrome and its treatment. Lung 186(Suppl 1):S94-S102.

Solan S, Wallenstein S, Shapiro M, Teitelbaum SL, Stevenson L, Kochman A, Kaplan J, Dellenbaugh C, Kahn A, Biro FN, et al. 2013 Cancer Incidence in World Trade Center rescue and recovery workers, 2001-2008. Environ Health Persp 121:699-704.
Tarlo SM. 2000. Workplace respiratory irritants and asthma. Occup Med 15:471-484.

Weakley J, Webber MP, Gustave J, Kelly K, Cohen HW, Hall CB, Prezant DJ. 2011. Trends in respiratory diagnoses and symptoms of firefighters exposed to the World Trade Center disaster: 2005-2010. Prev Med 53:364-369.

Weakley J, Webber M, Fen Y, Zeig-Owens R, Cohen HW, Hall CB, Kelly K, Prezant DJ. 2013. Agreement between obstructive airways diseases diagnoses from self-report questionnaires and medical records. Prev Med 57:38-42.

Webber MP, Glaser MS, Weakley J, Soo J, Ye F, Zeig-Owens R, Weiden MD, Nolan A, Aldrich TK, Kelly K, et al. 2011. Physiciandiagnosed respiratory conditions and mental health symptoms 7-9 years following the WTC disaster. AJIM 54:661-671.

Weiden MD, Ferrier N, Nolan A, Rom WN, Comfort A, Gustave J, Zeig-Owens R, Zheng S, Goldring RM, Berger KI, et al. 2010. Obstructive airways disease with air trapping among firefighters exposed to World Trade Center dust. Chest 137(3):566-574.

Wheeler K, McKelvey W, Thorpe L, Perrin M, Cone J, Kass D, Farfel M, Thomas P, Brackbill R. 2007. Asthma diagnosed after 11 September 2001 among rescue and recovery workers: Findings from the World Trade Center health registry. Environ Health Persp 115:1584-1590.

WTC Operational Statistics. 2011. Retrieved March 17, 2015, from http://www.nyc.gov/html/ocme/downloads/pdf/public_affairs_ocme_ pr_WTC_Operational_Statistics.pdf.

Youakim S. 2001. Work-related asthma. Am Fam Physician 64:1839-1848.

Yu S, Brackbill RJ, Stellman SD, Ghuman S, Farfel M. 2015 Evaluation of non-response bias in a cohort study of World Trade Center terrorist attack survivors. BMC Research Notes 8:42.

Zeig-Owens R, Webber M, Hall CB, Schwartz T, Jaber N, Weakley J, Rohan TE, Cohen HW, Derman O, Aldrich TK, et al. 2011. Early Assessment of cancer outcomes in New York City firefighters after the September 11. Attacks Lancet 378:898-905.

\section{SUPPORTING INFORMATION}

Additional supporting information may be found in the online version of this article at the publisher's web-site.

The work was performed at the New York City Department of Health and Mental Hygiene. 